\title{
Risk behaviors at late childhood and early adolescence as predictors of depression symptoms
}

\author{
Renata Sikora
}

\author{
Cardinal Stefan Wyszynski University, Warsaw
}

\begin{abstract}
The study aims to answer following questions: (1) What are the risk behaviors among children at late childhood and early stage of adolescence? (2) What are the differences between boys and girls concerning problem behaviors? (3) Do risk behaviors predict symptoms of depression? Participants fulfilled the set of three tools: (1) Children Depression Inventory authored by M. Kovacs (1992); (2) List of experienced risk behaviors and (3) List of open questions concerning the knowledge and experience with smart drugs. The study group consisted of 130 boys and girls attending the fifth and sixth grade of primary school. The study shows differences between boys' and girls' risk behaviors, as well as the similarities. The findings indicate that gender-related disparities in problem behaviors exist even at the early stages of puberty. Boys under one parent custody declare significantly more risk behaviors than girls under one parent custody. Finally, the symptoms of depression were predicted by cumulative number of risk behaviors and - on tendency level - by type of parental custody.
\end{abstract}

Keywords: risk behavior, depression, adolescence

\section{Introduction}

Risk behaviors gain much attention since they are strongly connected with psychopathology and psychological condition of adolescents. Much is known about the origin and types of these behaviors yet this knowledge concerns individuals in middle or late adolescence $[1,2]$. Children entering the early stages of adolescence are thought not to be the high-risk group and therefore the research in this area is meagre. It seems, however, important to check - if and precisely what risk behaviors are present at late childhood and early periods of adolescence. Subsequent issues to be answered concern risk behaviors as predictors of depression symptoms.

Risk behaviors are often defined as those threatening one's psychological, physical and sometimes even social well-being [3]. Among them most often are placed: alcohol drinking; tobacco, cannabis or marihuana smoking; sexual activity including early age of first coitus; truancy and dropping out of school; violence and bullying; medicine, drug or smart drug intake. $[1,5,6]$. Less often are poor financial management (debts and money commitments), carrying gun, delinquent behaviors, fast driving, suicide ideations or attempts $[1,5,7]$. Such activities as watching programs for adults, putting personal info on the internet, seeking sensation via accompanying someone who is driving fast or making friends with older individuals are not defined as risk behaviors but might be described as 'pre-risk' ones. This is because they are often connected with further aggression, risky sexual activity or substance use. Taking the medical and psychological perspective, risk behaviors are in opposition to pro-health practices such as sports activity, healthy diet, strategies of problem solving and effective emotion regulation [8].

It is essential to consider both the sex and age of individuals when looking for risk behaviors as forerunners of youngsters' depression. Researchers have noticed that girls are more likely to internalize their problems, while boys tend to externalize problems [8]. These differences, however, are neither plain nor clear. Both girls and boys experiment with drinking alcohol, smoking cigarettes and engaging in risky sex [4,5]. Girls are more prone to feel anxiety, sadness and report lower physical and/or psychosocial functioning $[4,9]$. Boys declare bullying and oppositional-defiant behaviors, carrying some kind of gun, dropping out of school, and figure in police statistics [1]. Also, boys are ten times more likely to commit suicide [8]. The percentage of girls and boys experimenting with risk responses are different depending on age of adolescents $[1,4,10]$. Gender-related differences appear at early stages of puberty and they grow with age. The knowledge of girls' risk behaviors has yet to be completed - except for their sexual activity [11]. This might be due to methodology (question content) or a different study approach. Surprisingly, numerous studies are either focused on boys only or on mixed, gender balanced group. Yet, there are not many gender specifications concerning types of risk behaviors $[1,5,6]$. It is then a need to fill this gap in - especially when the emergence of risk behaviors is observed. 
There is a clear relationship between the age of adolescents and both the presence and type of these problems. Lynn Rew, Sharon Horner and Adam Brown (2011) revealed that among 13-year olds tobacco smoking was declared by $11 \%$ of participants. In addition, $12 \%$ declared having tried marijuana and $24 \%$ admitted to drinking alcohol. Ruey-Hsia Wang and colleagues (2010) found that in the group of 15 -year-olds $16.5 \%$ drank alcohol, $11 \%$ regularly smoked tobacco, $10 \%$ had an experience of first coitus, $73 \%$ have been bullying both at school and in home environment and 33\% had suicidal ideations. Late adolescents declared binge drinking (50\% of asked 18-yearold boys), regular usage of cannabis (14\%) smoking cigarettes (40\%) and regular school truancy (82\%). Furthermore, $21 \%$ of boys in this study had some kind of debt and $10 \%$ were recorded in police statistics [1]. Justin Jager and Pamela Davis-Kean (2011) found that 16\% of 17 year-olds had risky homosexual sex (not as a sexual orientation need but as a form of novelty exploration). Over $50 \%$ of participants used the internet for nude or half nude pictures publication, sexting, partner picking and/or poaching. Sexual practices - especially early age of coitus and numerous partners are also connected with threatening indices of STI (sexual transmitted infections) [12]. In sum, the age of adolescents is connected with higher rates of risk behaviors and their types.

Exposure to anti-health behavior put children at risk for further consequences e.g. poor psychological and physical condition, addictions, early parenthood, social awkwardness and the most threatening - as far as suicide trials are concerned - depression $[13,14]$. Some researchers state that preadolescent or early adolescent risk behaviors are developmental norms and they will disappear - after some escalation in mid or late puberty time - in adulthood [15]. Contrary to such assumption are estimations that at least one third of adolescents will not drop problem behaviors but rather carry them into a grown up life [4]. Depression indices published in health statistics are appalling (see: http://www.who.int/ mediacentre /factsheets/ fs369/en/). Yet, the relationship between psychiatric symptoms in youngsters e.g. constant anxiety, fear, dysphoria, anhedonia, low mood and risk behaviors are still unclear. For example the comorbidity of conduct problems and depression is estimated as medium or high [9]. The relation between depression and risk sexual activity undertaking has been proved for girls but not for boys. [7]. Drinking alcohol and smoking may be connected with high levels of risk undertaking since lack of ability to manage emotion regulation is often manifested through substance consumption $[4,16]$. No clear answer - according to the author's knowledge - is obtained on relation between various types of risk behaviors and practices that might be described as pre-risky and symptoms of depression. The study aim is to answer following questions:
(1) What are risk behaviors in children at early stages of adolescence?

(2) Are there any differences between boys and girls concerning prevalence and types of risk behaviors?

(3) Are risk behaviors connected with depression?

\section{Material and Method}

\section{Tools}

Participants were asked to fill out three tools. (1) Children Depression Inventory authored by Maria Kovacs [17] is well-known and often used measure of depression in children and adolescents aged 7 till 17. It consists of 27 items concerning symptoms of depression, among them dysphoria, anhedonia, change in sleep and nutrition habits, indecisiveness, anxiety, fear, suicide ideation, conflict with peers and adults, low self-esteem. Each item consists of three statements. Participants indicate one which describes their feelings or cognition best. The more depressive the statement is, the higher score it receives (possible scores for each item are: " 0 " - when there is no presence of symptom, " 1 " - when the symptom is present or "2" when the symptom is severe). The maximum score is 54 points. Kovacs [17] proposes the following interpretation of final score: 0-10 points - no depression, 11-18 points - low or middle level of depression and 19 or more points - heavy depression in child/adolescent perception. CDI scale presents good psychometric indices: test - retest was measured by Finch and colleagues in 14 days and equalled $r=0,82$ [17] .

(2) The data on what possible problem or risk behaviors might concern 10, 11 and 12-year-old participants were gathered from various sources: children, their parents, school staff and via literature research. Specifically, in pilot procedure 22 pupils were asked "What possible anti-health and risk behaviors may concern individuals at your age?". In anonymous letters they proposed altogether 11 categories of risk behaviors (30 particular behaviors) and their parents wrote down only 5 problem behaviors in similar letter procedure. Information was also collected through interviews with school staff. Next, three competent judges decided which risk behavior should be put on the list. The agreement rate was high (over 90\%). Finally 11 behaviors were chosen to constitute list of risk behaviors. Among them were: sensation seeking, alcohol drinking or consumption, smoking cigarettes, smart drug consumption/intake, late home comeback, watching programs for adults, succumbed behavior to others, putting personal data on the internet (see the note above the Table 1). The list maximum score was 11 points (when participant declared experience of all proposed behaviors). The minimum score was 0 points (when participant declared no experience of risk behavior). 
Test retest reliability ratio after a seven days period, measured in group of 22 adolescents was $r=0.76$.

(3) The third tool was a list of open questions concerning pupils' possible experience with smart drugs. One of its items ("I tried/used a substance which changed my consciousness") was also an item on list of risk behaviors. The other answers are not presented in this paper.

Participants also answered a few demographic questions - concerning their sex, age, parents and living conditions (city versus village).

\section{Participants and procedure}

The study is partly a result of a research conducted upon school authorities' request. Specifically, the school in which the study was conducted was obliged by city authorities to define whether fifth and sixth graders had experimented with smart drugs and what is their knowledge about the issue. It was additionally decided to add, more questions concerning other risky behaviors and to find out whether they are connected to participants' perceived depression. Parents' opinion and consent was gathered from the parents' school council. Children were asked to fulfil materials but the participation was voluntary.

134 individuals took part in the study. One person refused the participation. 4 sets of received tools were excluded from the further analysis as they had too many gaps. Finally the study group consisted of 130 fifth and sixth graders. Among them were 73 girls (56\%) and 57 boys (44\%). The average age of participants was $\mathrm{M}=11,38(\mathrm{SD}=0,72)$. 100 children lived with two parents (77\%); 27 with one parent - most often mother $(21 \%)$ and 3 with non-biological caregiver or grandparents (2\%). Participants lived mostly in the school district (city center). The criterion of study group sampling was age and sex of participants. It was assumed that individuals entering the age of adolescence will participate and the representation of both sexes will be equal. This scope was not reached for boys absence at school was higher than girls'.

The meetings were taking place in school classrooms, with no teacher presence. Each meeting lasted for about 25-30 minutes, including initial information and explaining both the aim and conditions for participating in the study. Participants were assured to remain anonymous at each stage of the study.

\section{Results}

Data showing percentile ratio of participants who declared experience with behaviors put on list of risk behaviors are presented in Table 1.

Note: The table items content was as follows: 1. "I drank beer" 2. "I drank wine, vodka or other strong alcoholic drink" 3. "I smoked a cigarette" 4. "I accepted being with someone overspeeding in one car" 5. "I like jumping from high altitude"
6. "I sometimes come back home late at night" 7. " Most of my friends are much older than I am" 8. "I did something because someone pushed me but I did not want to" 9. "I have put some personal information online" 10. "I watch TV programs for adults", 11. "I tried a substance that changed my conscience".

Table 1. Risk behaviors at late childhood and early adolescence

\begin{tabular}{|c|l|c|c|}
\hline No & \multicolumn{1}{|c|}{ Risk behaviors } & $\begin{array}{l}\text { Participants } \\
\text { ratio (\%) }\end{array}$ & Range \\
\hline 1 & Beer consumption & 32 & 5 \\
\hline 2 & Wine/vodka consumption & 20 & 8 \\
\hline 3 & Smoking cigarettes & 6 & 9 \\
\hline 4 & Acceptance for overspeeding & 86 & 1 \\
\hline 5 & High altitude jumping & 58 & 2 \\
\hline 6 & $\begin{array}{l}\text { Companionless, late home } \\
\text { comeback }\end{array}$ & 24 & 7 \\
\hline 7 & Preference of older others & 27 & 6 \\
\hline 8 & $\begin{array}{l}\text { Succumbed conduct towards } \\
\text { others }\end{array}$ & 35 & 4 \\
\hline 9 & $\begin{array}{l}\text { Putting personal info on the } \\
\text { internet }\end{array}$ & 5 & 10 \\
\hline 10 & Watching shows for adults & 49 & 3 \\
\hline 11 & $\begin{array}{l}\text { Drug or psychoactive sub- } \\
\text { stance intake }\end{array}$ & 7 & 9 \\
\hline
\end{tabular}

Risk behaviors that were declared most often were as follows: accompanying somebody while fast driving, jumping from dangerous heights (at risk of contusion or leg/hand braking), watching programs containing violence/erotic scenes. Participants also declared drug, smart drug or medicine taking, as well as smoking cigarettes and putting personal information on the Internet.

The differences between boys' and girls' declarations of risk behaviors are presented in Table 2 .

Table 2. Gender differences in risk behaviors.

\begin{tabular}{|c|l|c|c|c|c|}
\hline No & \multicolumn{1}{|c|}{ Risk behaviors } & $\begin{array}{c}\text { Girls } \\
\text { (\%) }\end{array}$ & $\begin{array}{c}\text { Boys } \\
\text { (\%) }\end{array}$ & Ch2 & p \\
\hline 1 & Beer drinking & 27 & 37 & 1,312 & 0,252 \\
\hline 2 & Wine/vodka drinking & 14 & 30 & $\mathbf{5 , 0 1}$ & $\mathbf{0 , 0 2 5}$ \\
\hline 3 & Smoking cigarettes & 5 & 7 & 0,13 & 0,718 \\
\hline 4 & $\begin{array}{l}\text { Acceptace for } \\
\text { overspeeding }\end{array}$ & 85 & 82 & 0,319 & 0,572 \\
\hline 5 & High altitude jumping & 53 & 59 & 0,359 & 0,549 \\
\hline 6 & $\begin{array}{l}\text { Companionless, late } \\
\text { home comeback }\end{array}$ & 18 & 31 & $\mathbf{3 , 3 1 7}$ & $\mathbf{0 , 0 6 9}$ \\
\hline 7 & $\begin{array}{l}\text { Preference of older } \\
\text { others }\end{array}$ & 28 & 23 & 0,286 & 0,593 \\
\hline 8 & $\begin{array}{l}\text { Succumbed conduct } \\
\text { towards others }\end{array}$ & 40 & 26 & $\mathbf{3 , 0 6 6}$ & $\mathbf{0 , 0 8}$ \\
\hline 9 & $\begin{array}{l}\text { Putting personal info on } \\
\text { the internet }\end{array}$ & 3 & 7 & 1,302 & 0,251 \\
\hline 10 & $\begin{array}{l}\text { Watching shows for } \\
\text { adults }\end{array}$ & 48 & 44 & 0,327 & 0,567 \\
\hline 11 & $\begin{array}{l}\text { frug or psychoactive } \\
\text { substance intake }\end{array}$ & 5 & 10 & 0,111 & 0,721 \\
\hline
\end{tabular}

Note: The results at point 6 . and 8 . show differences on tendency level. $\mathrm{N}$ (boys) = 57; $\mathrm{N}$ (girls) $=73$ 
There were no differences concerning the total number of risk behaviors between girls $(M=3,47$; $\mathrm{SD}=2,21)$ and boys $(\mathrm{M}=3,92 ; \mathrm{SD}=2,24) \mathrm{t}=-1,142, \mathrm{p}=0,256$.

The parental care of one parent (most often mother) is different than joint custody or nuclear family attention [18]. Thus the possible difference between risk behaviors in children under one parent custody were searched. The results are presented in Table 3 .

Table 3. Gender differences in risk behaviors in children living with one parent

\begin{tabular}{|l|c|c|c|c|c|c|}
\cline { 2 - 5 } \multicolumn{1}{c|}{} & \multicolumn{2}{c|}{$\begin{array}{c}\text { Girls } \\
\text { (n= 73) }\end{array}$} & \multicolumn{2}{c|}{$\begin{array}{c}\text { Boys } \\
\text { (n= 57) }\end{array}$} & \multirow{2}{*}{ t } & \multirow{2}{*}{ p } \\
\hline $\begin{array}{l}\text { Total number of } \\
\text { experienced risk } \\
\text { behaviors }\end{array}$ & $\mathrm{M}$ & $\mathrm{SD}$ & $\mathrm{M}$ & $\mathrm{SD}$ & & \\
\cline { 2 - 6 } & 3.22 & 1.98 & 5.33 & 2.64 & 2.11 & 0.05 \\
\hline
\end{tabular}

Boys living with one parent declared significantly more risk behaviors than girls who also lived with one parent. Such a difference was not present when total number of risk behavior was computed for boys and girls living with two parents.

The comparison of the level of depressive symptoms between boys and girls was not found to be significant (girls' $M=11,00 ; S D=6,04$ and boys' $M=9,88 ; S D=6,11$; $t=1,113 ; p=0,215)$. The level of depressive symptoms in the whole group of participants was $M=10,44 ; S D=6,57$.

To answer the question whether risk behaviors are related to the symptoms of depression a regression analysis was conducted. Four predictors were included into the model: age, sex, two versus one parent custody, and a total number of experienced risk behaviors. The influence of these factors was significant. The results of the analysis are presented in table 4 .

Table 4. Depressive symptoms predictors in children and adolescents

\begin{tabular}{|l|c|c|}
\hline $\begin{array}{l}\text { Predictors of perceived } \\
\text { depression }\end{array}$ & $\mathbf{B}$ & $\mathbf{p}$ \\
\hline Age & 1,204 & 0,350 \\
\hline Sex & $-1,033$ & 0,109 \\
\hline Type of parental care & $-1,193$ & $-0,080$ \\
\hline Risk/pre-risk behavior & 1,107 & 0,001 \\
\hline \multicolumn{2}{|c|}{$\mathrm{F}(4,125)=6,792 ; \mathrm{p}=0,001 ; \mathrm{r}=0,423$} \\
\hline
\end{tabular}

Both 'age' and 'sex' variables were not significant in predicting depression symptoms in children and adolescents. Type of 'parental custody' - i.e. one parent care was a predictor on tendency level. Risk behaviors - the total number according to participants' declarations - explained $18 \%$ of variance of the perceived depression rates in 10-12-year-old children and adolescents.

\section{Discussion}

Children at late childhood and early adolescence experience specific risk behaviors. It is not a common knowledge since majority of the research focuses on mid and late puberty periods. As previous research has shown these particular conducts - connected with psychological consequences are carried - by at least some of children into adolescence and adulthood and put them subsequently in further risk of suicide, various addictions, poor mental functioning and worse social conditions [4]. Thus, the knowledge of these forerunners is important for parents, medical caregivers, psychiatrists, psychologists and teachers.

While at later stages of development risk behaviors are either seriously threatening to health (like regular smoking, binge drinking, risky sex, drug intake) or of delinquent background (truancy, debt, minor theft, escaping home) at early stages of adolescence they are different. According to declarations of 10 - and 12-year-old pupils these are: sensation seeking via accompanying someone who's driving fast, jumping from high altitudes, watching violent/erotic shows for adults, alcohol drinking and cigarette smoking, succumbed behavior toward others, putting personal information on the internet page(s), late home comeback and preference of friendships with older colleagues. These behaviors are risky and some of them also lead to further risk forming cumulative effect. Drinking alcohol is connected with earlier age of first sexual intercourse, damaging one's property, risky driving, aggression toward others, poor social networks $[12,13,17]$. Watching TV, playing video games and making friends with older people deepen unbeneficial modeling effect $[13,17]$. Both smoking and experiments with different substances such as medicines open paths for drugs, smart drugs and other psychoactive addictions [16]. It is then important to keep this in mind especially that children are more active in this field than their caregivers expect (who of them would think that swallowing matches, playing with sharp knife, cutting skin, Spiritism, strict diet or wearing inadequate to the weather clothes just to show off is a practice among their children or pupils?) ${ }^{1}$.

According to the study, some risky behaviors are gender specific. There were three differences between girls and boys - two of them, were on the statistical tendency level . First, more boys have drunk or at least tried wine or vodka. Girls were more prone to succumb toward others (an item: 'I did something because someone pushed me but I did not want to do it'). The last difference showed that boys more often than girls came back home alone later than at $10 \mathrm{pm}$. Previous studies also showed gender differences, yet they considered different risk behaviors and emerging at later stages of adolescence [4,5]. An additional and supplementing the gender-specific information is that in particular risk group are boys living with one parent (most often mother).

1 These risky behaviors are citations from anonymous letters of children participating in the study. None of them were mentioned by parents or school staff. 
Cumulative effect of risk behaviors experience on depression symptoms emergence was showed in the study. Similar relation has been presented in previous studies. For example Rienke Bannik, Suzane Broeren, Jurriën Heydelberg, Els van't Klooster and Hein Raat (2015) found that two clusters of risk behaviors (1. binge drinking, smoking cannabis/cigarettes and 2. registration in a police statistics, delinquent behavior, school truancy) were predicting depression in 18-year-old boys. Others found that opposite defiant behaviors or problem behaviors (at least two risk behaviors coexisting) are related to depression $[9,19]$. This study, however, points that experience of behaviors which might be described as forerunners of typical risk behavior is also related to the perceived depression in 10, 11 and 12-year-old boys and girls.

\section{Conclusions}

The most important findings of the study show that problem behaviors in individuals aged 10-12 are different from those declared by older adolescents. Risky behaviors at early stages of adolescence might be gender-specific. In the study, boys declared drinking alcohol and companionless late home comeback more often than girls. In turn, girls were more likely to do something when pressed to by others (peer pressure). Thus, the study brings a consideration for gender-specific protective programs. It also puts in light possible consequences of one parent custody for males, as boys living with one parent declared significantly more risk behaviors than girls who also lived with one parent. Such differences were not found when children living with two parents were compared. Finally, even these 'light' risk behaviors - the antecedents of seriously health threatening ones - are connected with adolescents' perceived depression, as study proved.

\section{References:}

1. Bannik R., Broeren S., Heydelberg J. Klooster E. Raat H. Depressive symptoms and clustering of risk behaviors among adolescents and young adults attending vocational education: a cross sectional study. Publ Health, 2015; 15 (4): 2-9.

2. Kosunen E.E., Kaltiala-Heino R., Rimpelä M., Laippala P. Risk taking sexual behavior and self-reported depression in middle adolescence - a school based study. Child: Care, Health Dev, 2003; 29 (5): 337-344.

3. Kosterman R., Hawkins D., Mason A., Herrenkohl T., Lengua L., McCauley E. Assessment of behavior problems in childhood and adolescence as predictors of early adult depression. J of Psychopath \& Beh Assessment, 2009; 32 (1): 118-127.

4. Bobrowski K., Czabała Cz., Bykczyńska C. Risk behaviors as a dimension of mental health assessment in adolescents. Arch Psychiatr Psychotherapy, 2007; 1-2: 17-26.

5. Rew L., Horner S.D., Brown A. Health risk behaviors in early adolescence. Issues Comp Ped Nurs, 2011; 34: 79-96.
6. Wang R.H., Hsu H.Y., Lin S.Y., Cheng Ch. P., Lee S.L. Risk behaviors among early adolescents: risk and protective factors. J Adv Nurs, 2010; 66 (2): 313-323.

7. Meier A. Adolescent First Sex and Subsequent Mental Health. American Journal of Sociology, 2007; 112 (6): 1811-1847.

8. Eriksson I., Cater A., Andershed A.K., Andershed H. What protects youths from externalizing and internalizing problems? Critical review of research findings and implications for practice. Journal of Guidance and Counselling, 2011; 21 (2): 113-125.

9. Wolff J., Ollendick T.H. The comorbidity of conduct problems and depression in childhood and adolescence". Clinical Child \& Family Psychology Review, 2006; 9 (3-4): 201-220.

10. Zalk N., Kerr M., Tilton-Weaver L. Shyness as a moderator of the link between advanced maturity and early adolescent risk behavior. Scandinavian Journal of Psychology, 2011; 52 (4): 341-353.

11. Avery L., Lazdane G. (2008). What do we know about sexual and reproductive health of adolescents in Europe. The European Journal of Contraception and Reproductive Health Care, 2008; 13 (1): 58-70.

12. Jager J., Davis-Kean P. Same sex sexuality and adolescent well-being: the influence of sexual orientation, early reports on same-sex attraction, and gender. Self and Identity, 2011; 10 (4): 417-444.

13. Jackson Ch., Brown J., Pardum C. A TV in bedroom: implications for viewing habits and risk behaviors during early adolescence. Journal of Broadcasting \& Electronic Media, 2008; 52 (3): 349-367.

14. Ward L. Does television exposure affect emerging adults' attitudes and assumptions about sexual relationships? Correlational and experimental confirmation. Journal of Youth \& Adolescence, 2002; 31 (1): 1-15.

15. Guardini T., Marks A., Patton F., Coll C. The immigrant paradox in sexual risk behavior among Latino adolescents: impact of immigrant generation and gender. Appl Dev Sci, 2011; 15 (4): 201-209.

16. Shanklin S., Brener N., Kann L., Griffin-Blake S., Ussery-Hall A., Easton A., Barrett E., Hawkins J., Harris W.A., McManus T. Youth Risk Behavior Surveillance - Selected Steps Communities, Surveillance Summaries, 2007; 57 (12): 1-26.

17. Rola J. Upośledzenie umysłowe jako czynnik ryzyka dla depresji dziecięcej. Warszawa; Wydawnictwo WSPS: 1996.

18. Falci $\mathrm{Ch}$. The effects of family structure and family process on the psychological well-being of children: from the children point of view. Master Thesis: Virginia Polytechnic Institute. Virginia USA; Blacksburg: 2006 https://theses.lib.vt.edu/theses /available/ etd-182516659751561/unrestricted/Falci.pd

19. Katon W., Richardson L., Russo J., McCarthy C., Rockhill C., McCauley E., Richards J., Grossman D. (2010). Depressive symptoms in adolescence: the association with multiple health risk behaviors. Gen Hosp Psychiatry, 2010; 32 (3): 233-239.

\section{Correspondence address}

Renata Sikora

rssikora@op.pl

ul. Miodowa $23 \mathrm{~m} 51$

00-246 Warszawa

Otrzymano: 16.07.2016

Zrecenzowano: 08.09.2016

Przyjęto do druku: 22.09.2016 